\title{
Pengaruh Penggunaan Kîbar Terhadap Keterampilan Membaca Bahasa Arab Pada Anak Disleksia
}

\author{
Silvi Tantri Wulandari ${ }^{1}$, \\ Ferawati $^{2}$, \\ ${ }^{1,2}$ Program Studi Bahasa dan Sastra Arab Universitas Ahmad Dahlan, Indonesia
}

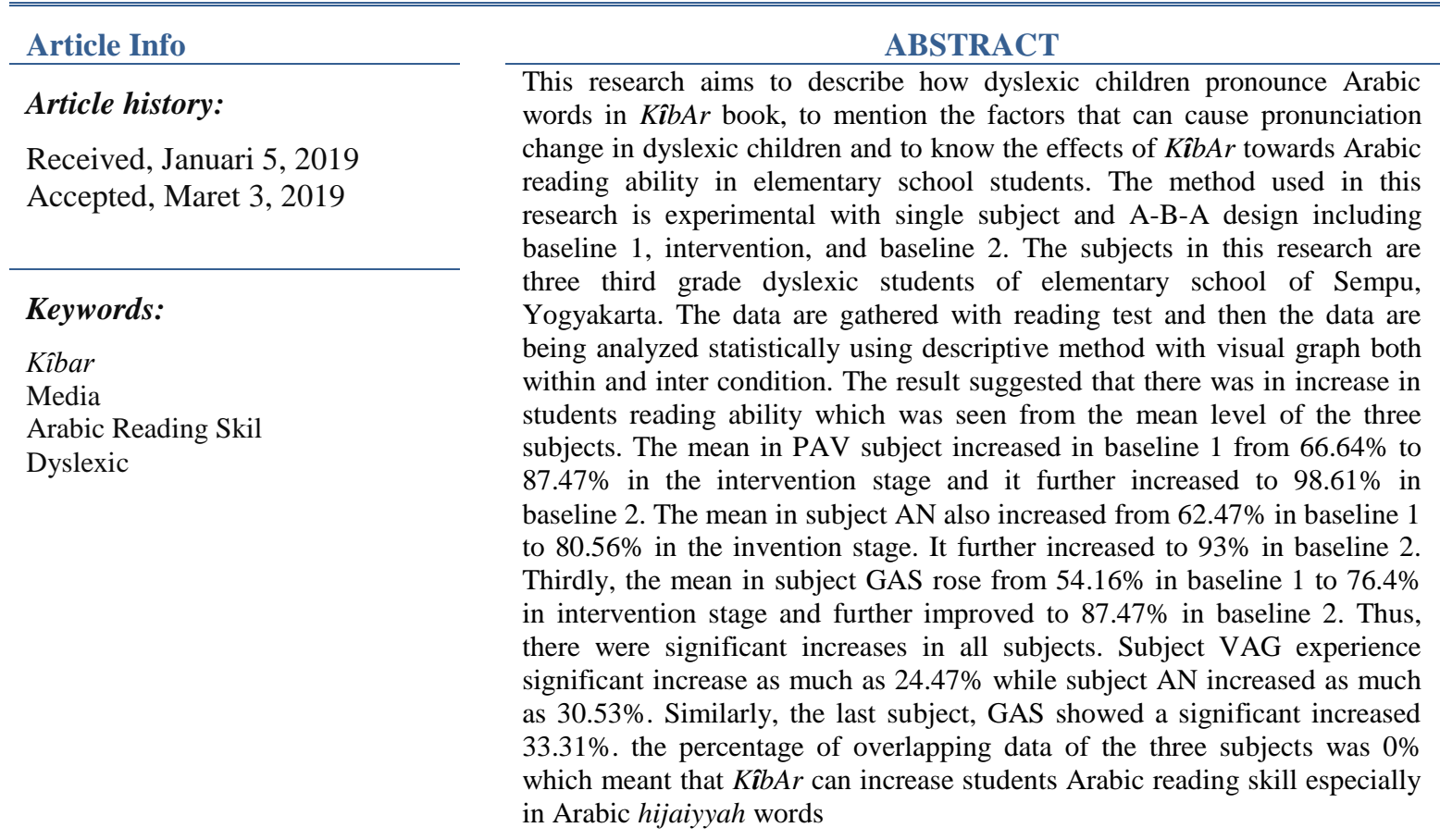

This is an open access article under the CC BY-SA license.

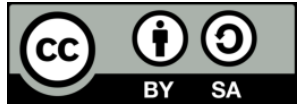

Corresponding Author:

Silvi Tantri Wulandari,

Program studi Pendidikan Agama Islam,

Universitas Ahmad Dahlan,

Email: silvi.wulandari @uad.ac.id

\section{PENDAHULUAN}

Bahasa merupakan sistem perlambangan yang secara arbitrer dibentuk atas unsur-unsur bunyi ucapan manusia dan digunakan sebagai sarana berinteraksi. Proses berinteraksi menggunakan bahasa diperlukan kemampuan bahasa yang baik. Kemampuan berbahasa yang baik dapat diperoleh apabila setiap orang mampu menguasai 4 tahapan dalam berbahasa yaitu mulai dari mendengarkan, berbicara, membaca, dan menulis. Dua tahap yang pertama berkaitan dengan bahasa lisan dan dua tahap terakhir berkaitan dengan bahasa tulisan (Darwojo 2008, 299). Apabila salah satu dari empat tahap tersebut tidak dapat dilalui dengan sempurna maka akan terdapat hambatan dalam pemerolehan bahasa. Terutama pada pemerolehan bahasa kedua atau bahasa asing salah satunya yaitu bahasa Arab.

Berbagai problematika atau kesulitan yang dihadapi dalam proses pembelajaran bahasa arab yaitu 1) problem linguistik yang terdiri dari problem tataran bunyi (musykilah ilm al-ashwat), problem kosakata 
(musykilah ilm al-mufradat), problem tata kalimat (musykilah al tarkib al-lughawiyah), problem tulisan (musykilah al-kitabah), 2) problem non linguistik yaitu tujuan, kurikulum, alokasi waktu, tenaga pengajar, siswa, metode, media, evaluasi, kebijakan pemerintah, lingkungan sosial, dan perbedaan sosiokultural masyarakat Arab dengan non Arab (Asyrofi 2014, 41-57). Problematika-problematika pemerolehan bahasa yang telah disebutkan di atas, selain mengalami hambatan dalam membaca anak-anak juga mengalami hambatan dalam hal menulis yang berkaitan dengan problem linguistik. Disleksia yang akrab disebut dengan kesulitan membaca termasuk dalam salah satu kategori penyimpangan atau kelainan dalam tingkah laku berbahasa (Mar'a 2005, 82).

Dislekssia termasuk dalam kategori patologi Bahasa yang merupakan bidang garap psikolinguistik dan berkaitan dengan empat topik utama: (a) komperhensif, yakni proses-proses mental yang dilalui oleh manusia sehingga mereka dapat menangkap apa yangb dikatakan orang dan memahami apa yang dimaksud, (b) produksi, yakni proses-proes mental pada diri kita yang membuat kita dapat berujar seperti yang ita ujarkan, (c) landasan biologis serta neurologis yang membuat manusia bisa berbahasa, dan (d) pemerolehan baasa, yakni bagaimana anak memperoleh bahasa mereka (Darwodjo 2008, 7).

Penelitian Nursara (2018) menyebutkan bahwa anak disleksia mengalami kesulitan dalam mengingat beberapa alphabet termasuk membedakan huruf yang terlihat hampir sama bentuknya pada alphabet bahasa Indonesia seperti dalam penelitian yang dilakukan oleh Siska Nursara (2018) di SD Negeri Sempu ditemukan subjek yang mengalami disleksia dengan kesulitan membedakan huruf yang hampir mirip bentuknya seperti p,q,b,d. Penelitian Helmanita dengan subjek dengan anak disleksia yang berinisial NYR (usia 7 tahun -iqra' 1) dan NRA (usia 10 tahun-iqra' 4) ditemukan beberapa kesalahan dalam membaca iqra' salah satunya, yaitu 1) subjek dengan inisial NRA membaca iqra' dengan kesalahan dua hal yakni kesamaan bentuk huruf seperti dibaca $\dot{\tau}$ ح, حdibaca $\dot{\tau}$ ج, dibaca ض, ص dibaca dan sebaliknya, 2) kesamaan bunyi seperti $ح$ dibaca • dan sebaliknya, ث dibaca w dan sebaliknya. Penelitianpenelitian di atas dapat memberikan kesimpulan bahwa subjek yang akan diteliti juga diasumsikan akan mengalami kesulitan dalam mempelajari huruf-huruf hijaiyah yang mempunyai kesamaan dalam hal bunyi dan bentuknya

Salah satu solusi yang dapat dilakukan untuk mengatasi permasalahan pada anak disleksia dalam berbahasa Arab yaitu dengan menggunakan media. Media KîbAr merupakan suatu buku yang dikembangkan dari IQRA' dan didesain sesuai karakteristik perkembangan anak-anak serta isinya lebih ditekankan pada pembelajaran makharijjul huruf termasuk peletakan huruf-huruf yang hampir sama dalam hal bentuk serta bunyi agar pembelajar dapat lebih mencermati perbedaan bunyi setiap hurufnya. KîbAr telah diterapkan pada salah satu TK KîbAr PLUS yang ada di Yogykarta dan telah dilakukan sebuah penelitian penggunaan KîbAr dengan metode KîbAr untuk anak usia dini oleh Maherlina Muna Ayuhana pada tahun 2012 bahwa hasil dari penelitian tersebut adalah penerapan metode KîbAr dapat meningkatkan kemampuan membaca al qur'an (Muna 2012).

Berbagai hal dan permasalahan yang telah dipaparkan di atas memberikan landasan bahwa dalam penelitian ini akan dikaji pengaruh penggunaan KîbAr terhadap kemampuan membaca bahasa Arab pada anak disleksia di SD Negeri Sempu. Berdasarkan uraian di atas, maka tiga pertanyaan yang ingin dijawab dalam peneltian ini. Pertama, bagaimana pelafalan kosakata Bahasa Arab pada anak disleksia terhadap buku KîbAr? Kedua, apa saja faktor penyebab perubahan pelafalan kosakata Bahasa Arab pada anak disleksia? Dan ketiga, bagaimana pengaruh penggunaan Kîb Ar terhadap ketrampilan membaca Bahasa Arab pada anak disleksia?

\section{METODE}

\subsection{Jenis penelitian}

Penelitian ini adalah penelitian eksperimen yang berusaha mencari pengaruh variabel tertentu terhadap variabel yang lain dalam kondisi yang terkontrol secara ketat. Desain penelitian eksperimen subjek tunggal yang digunakan yaitu desain reserval dengan pola A-B-A. penelitian ini terdapat intervensi individu (Hamid 2014, 43). Penelitian tersebut termasuk pada penelitian single subject research atau yang disebut SSR (Sunanto 2005, 29). Eksperimen tunggal dipilih dengan alasan sebagai berikut. Pertama, eksperimen ini dianggap paling cocok untuk meneliti manusia, terutama apabila perilaku yang diamati tidak mungkin diambil rata-ratanya. Kedua, faktor etis yaitu kelompok kontrol yang tidak menerima perlakuan (treatment), yang seharusnya mereka juga berhak untuk memperoleh intervensi. Terakhir, kecilnya ukuran populasi. Lebih dari itu, desain penggunaan kasus tunggal sering dipakai pada "clinical setting" tekanan pokoknya adalah pada efek terapi, bukan pada kontribusi pada pada efek terapi, bukan pada kontribusi pada landasan penelitian.

Penelitian dengan desain subjek tunggal selalu dilakukan perbandingan antara fase baseline dengan sekurang-kurangnya satu fase intervensi (Sunanto 2005, 54). Desain penelitian eksperimen subjek tunggal yang digunakan yaitu desain reserval dengan pola A-B-A. Desain reserval dengan pola A-B-A 
merupakan salah satu pengembangan dari desain dasar A-B. Pada desain A-B-A setelah pengukuran pada kondisi intervensi (B) pengukuran pada kondisi baseline kedua (A2) diberikan. Penambahan kondisi baseline kedua (A2) ini dimaksudkan sebagai kontrol untuk fase intervensi sehingga memungkinkan untuk menarik kesimpulan adanya hubungan fungsional antara variabel bebas dan variabel terikat. Struktur desain A-B-A adalah seperti digambarkan di bawah ini (Sunanto et al 2005, 59).

\subsection{Tempat dan Waktu Penelitian}

Penelitian ini dilaksanakan di SD Negeri Sempu, Temben, Sleman, Yogyakarta yang dilaksanakan pada tanggal 29, 30 Maret dan 5, 6, 11-13 April 2019.

\subsection{Subjek dan Penelitian}

Subjek penelitian ini adalah siswa SD Negeri Sempu. Subjek penelitian tersebut adalah siswa yang mengalami kesulitan belajar spesifik (disleksia) sebanyak 3 orang (PAV, AN, dan GAS) dengan identitas dan karakteristik dari hasil analisis psikolog. Objek yang digunakan dalam penelitian ini berupa KîbAr. KîbAr merupakan suatu media hasil inovasi IQRA' yang didesain lebih menarik dan sesuai dengan karakteristik anak-anak. Variabel bebas dalam penelitian ini yaitu berupa media KîbAr. Penelitian eksperimen ini memiliki single subject dengan dua variabel yaitu variabel bebas (variabel eksperimental) dan variabel terikat. Variabel terikat yang dimaksud dalm penelitian ini berupa anak disleksia di SD Negeri Sempu Yogyakarta.

\subsection{Variabel Penelitian}

Penelitian ini merupakan penelitian single subject dengan dua variable, yaitu variable bebas (variable eksperimental) dan variable terikat. Variable bebas merupakan situasi atau stimulus yang dimanipulasi, sengaja dilakukan, dan kekhasan bentuk atau prosedurnya ditentukan oleh peneliti yang akan mempengaruhi variable terikat (Latipun 2015: 43). Variable bebas dalam penelitian ini adalah media KîbAr. Adapun variable terikat yang diobservasi dan dicatat oleh peneliti yang bentuknya berupa perilaku subjek yang hendak diukur (Latipun 2015: 44). Variable terikat dalam penelitian ini adalah siswa disleksia di SD Negeri Sempu.

\subsection{Teknik dan Instumen Pengumpulan Data}

Instrument penelitian ini menggunakan soal pada tes baseline 1 (IA) dan baseline 2 (A2). Instrumen non tes berupa dokumentasi dan observasi. Dokumentasi menggunakan instrumen ceklis, sedangkan observasi yang dilakukan pada baseline 1 (A1), intervensi (B) dan baseline 2 (A2) menggunakan ratting scale dan ceklis. Instumen lengkap tes ini seperti yang tertera di bawah ini.

1) Kisi-kisi soal tes

a) Tes awal (Baseline A1)

Baseline A1 digunakan pada tahap awal sebelum adanya intervensi yang berfungsi untuk mengetahui ketrampilan membaca siswa disleksia.

TABLE I. KISI-KISI INSTRUMEN BASELINE (1A)

\begin{tabular}{|c|c|c|c|c|c|}
\hline Sesi & Variabel & Aspek & Indicator & Jumlah butir soal & Nomor butir soal \\
\hline 1 , & Ketrampilan & Huruf hijaiyah & Kesamaan & 3 & $1,2,3$ \\
\hline 2 & membaca Bahasa & & bentuk & & \\
\hline Dan & Arab & & & & \\
\hline 3 & & & $\begin{array}{c}\text { Kesamaan } \\
\text { bunyi }\end{array}$ & 3 & $4,5,6$ \\
\hline
\end{tabular}

b) Tes kedua (intervensi)

Intervensi diberikan dengan menggunakan media KîbAr

TABLE II. KISI-KISI INSTRUMEN INTERVENSI (B)

\begin{tabular}{cccccc}
\hline Sesi & Variable & Aspek & Indicator & $\begin{array}{c}\text { Jumlah butir } \\
\text { soal }\end{array}$ & $\begin{array}{c}\text { Nomor halaman } \\
\text { Media KîbAr }\end{array}$ \\
\hline 1 & Ketrampilan & Huruf & Kesamaan bentuk & 2 & 2,4 \\
& membaca & hijaiyah & Kesamaan bunyi & 2 & 1,3
\end{tabular}




\begin{tabular}{|c|c|c|c|c|c|}
\hline & Bahasa Arab & & $\begin{array}{l}\text { Semua huruf } \\
\text { hijaiyah }\end{array}$ & 2 & 27 \\
\hline \multirow[t]{3}{*}{2} & \multirow{3}{*}{$\begin{array}{l}\text { Ketrampilan } \\
\text { membaca } \\
\text { Bahasa Arab }\end{array}$} & \multirow{3}{*}{$\begin{array}{c}\text { Huruf } \\
\text { hijaiyah }\end{array}$} & Kesamaan bentuk & 2 & 7,12 \\
\hline & & & Kesamaan bunyi & 2 & 5,6 \\
\hline & & & $\begin{array}{l}\text { Semua huruf } \\
\text { hijaiyah }\end{array}$ & 2 & 28 \\
\hline \multirow[t]{3}{*}{3} & \multirow{3}{*}{$\begin{array}{l}\text { Ketrampilan } \\
\text { membaca } \\
\text { Bahasa Arab }\end{array}$} & \multirow{3}{*}{$\begin{array}{c}\text { Huruf } \\
\text { hijaiyah }\end{array}$} & Kesamaan bentuk & 2 & 13,14 \\
\hline & & & Kesamaan bunyi & 2 & 7,8 \\
\hline & & & $\begin{array}{l}\text { Semua huruf } \\
\text { hijaiyah }\end{array}$ & 2 & 27 \\
\hline \multirow[t]{3}{*}{4} & \multirow{3}{*}{$\begin{array}{l}\text { Ketrampilan } \\
\text { membaca } \\
\text { Bahasa Arab }\end{array}$} & \multirow{3}{*}{$\begin{array}{c}\text { Huruf } \\
\text { hijaiyah }\end{array}$} & Kesamaan bentuk & 2 & 15,18 \\
\hline & & & Kesamaan bunyi & 2 & 10,11 \\
\hline & & & $\begin{array}{l}\text { Semua huruf } \\
\text { hijaiyah }\end{array}$ & 2 & 28 \\
\hline \multirow[t]{2}{*}{5} & \multirow{2}{*}{$\begin{array}{l}\text { Ketrampilan } \\
\text { membaca } \\
\text { Bahasa Arab }\end{array}$} & \multirow{2}{*}{$\begin{array}{c}\text { Huruf } \\
\text { hijaiyah }\end{array}$} & Kesamaan bentuk & 2 & 20,21 \\
\hline & & & Kesamaan bunyi & 4 & $13,19,16$ \\
\hline \multirow[t]{2}{*}{6} & $\begin{array}{l}\text { Ketrampilan } \\
\text { membaca }\end{array}$ & \multirow[t]{2}{*}{$\begin{array}{l}\text { Huruf } \\
\text { Hijaiyah }\end{array}$} & Kesamaan bentuk & 4 & $24,25,26$ \\
\hline & Bahasa Arab & & Kesamaan bunyi & 2 & 17,22 \\
\hline
\end{tabular}

c) Tes Akhir (Baseline 2)

Baseline A2 merupakan tes yang diberikan pada taap ketiga setelah diberikan intervensi. Tujuan baseline A2 yaitu untuk mengetahui ketrampilan membaca Bahasa Arab pada anak disleksia setelah diberikan intervensi menggunakan media KîbAr.

TABLE III. KISI-KISI INSTRUMEN BASELINE 2 (A2)

\begin{tabular}{cccccc}
\hline Sesi & Variable & Aspek & Indicator & $\begin{array}{c}\text { Jumlah } \\
\text { butir soal }\end{array}$ & $\begin{array}{c}\text { Nomor butir } \\
\text { soal }\end{array}$ \\
\hline $\begin{array}{c}\text { Ketrampilan } \\
\text { dan }\end{array}$ & $\begin{array}{c}\text { Kembar } \\
\text { mema Bahasa } \\
\text { Arab }\end{array}$ & $\begin{array}{c}\text { Hijaiyah } \\
\text { hesamaan }\end{array}$ & $\begin{array}{c}\text { Kentuk } \\
\text { Kesamaan } \\
\text { bunyi }\end{array}$ & 3 & $1,2,3$ \\
\hline
\end{tabular}

Perhitungan skor pada saat dilakukannya tes yang digunakan adalah rating scale, yaitu 'data mentah yang diperoleh berupa angka kemudian ditafsirkan dalam pengertian kualitatif' (Sugiyono, 2016: 97). Berikut ini skala penilaian pada penelitian ini.

TABLE IV. Kriteria SKor PEnLIAIAN Tes MEMBACA

\begin{tabular}{cc}
\hline Skor & Kriteria \\
\hline 1 & Dapat membaca semua huruf hijaiyah dengan bantuan guru \\
2 & Dapat membaca huruf hijaiyah sebanyak 50\% dari jumlah soal secara mandiri \\
3 & Dapat membaca semua huruf hijaiyah dengan lafal yang tepat disertai sedikit bantauan guru \\
4 & Dapat membaca semua huruf hijaiyah dengan lafal yang tepat secara mandiri \\
\hline
\end{tabular}


Skor yang diperoleh melalui kegiatan membaca dan menulis tersebut kemudian diubah dalam bentuk presentasi. Rumus penliaian yang digunakan dalam penelitian ini yaitu (Purwanto, 2013: 102):

$\mathrm{NP}=\frac{\text { Skor yang diperoleh }}{\text { Skor maksimum }} \times 100$

Keterangan:

$\mathrm{NP}=$ Nilai persen yang dicari

$\mathrm{R}=$ Skor mentah yang diperleh siswa

$\mathrm{SM}=$ Skor maksimum ideal dari tes

$100=$ Bilangan tetap

\subsection{Validitas dan Reabilitas Instrumen}

Validitas yang digunakan dalam penelitian ini berupa validitas isi (content validity) yang menunjukkan pada suatu instrument yang memiliki kesesuaian isi dalam mengungkap/mengukur yang akan diukur (Margono 2014, 188). Jenis reabilitas yang digunakan dalam penelitian ini adalah r Pearson.

\subsection{Teknik Analisis Data}

Metode analisis yang digunakan dalam penelitian ini adalah metode analisis visual dengan analisis perubahan dalam kondisi dan analisis antar kondisi.

1) Analisis Grafik

Analisi visual grafik meliputi analisis dalam dantar kondisi dengan beberapa komponen sebagai berikut (Sunanto, et al 2005, 104).

a. Komponen analisis dalam kondisi

1. Panjang kondisi

2. Estimasi kecenderungan arah

3. Kecenderungan stabilitas

4. Jejak data

5. Level stabilitas dan rentang

6. Level perubahan

b. Analisis antar kondisi

1. Jumlah variable yang diubah

2. Perubahan kecenderungan arah dan efeknya

3. Perubahan stabilitas

4. Perubahan level

5. Data overlap

c. Langkah-langkah analisis dalam kondisi

Langkah-langkah analisis dalam kondisi (Sunanto, et al 2005, 108) adalah sebagai berikut:

\section{Langkah ke 1}

Isi baris perama huruf kapital sesuai dengan kondisinya misalnya (A1) untuk baseline 1,

(B) untuk intervensi dan (A2) untuk baseline 2.

\section{Langkah ke 2}

Menurut panjang interval, panjang interval menunjukkan ada beberapa sesi dalam kondisi tersebut.

\begin{tabular}{llll}
\hline Kondisi & \multicolumn{1}{c}{$\mathrm{A} / 1$} & $\mathrm{~B} / 1$ & $\mathrm{~A} / 2$ \\
\hline $\begin{array}{l}1 . \text { Panjang } \\
\text { kondisi }\end{array}$ & $\ldots \ldots$ & $\ldots \ldots$ & $\ldots \ldots$ \\
\hline
\end{tabular}

Langkah ke 3

Mengestimasi kecenderungan arah dengan menggunakan metode belah dua (spilt-middle)

\begin{tabular}{llll} 
Kondisi & $\mathrm{A} / 1$ & $\mathrm{~B} / 1$ & $\mathrm{~A} / 2$ \\
\hline 2.Estimasi & $\ldots .$. & $\ldots \ldots$ & $\ldots \ldots$ \\
kecenderungan Arah & $(\mathrm{)}$ & $(\mathrm{)}$ & $($ )
\end{tabular}

Langkah ke 4

Menentukan kecenderungan stabilitas

Skor tertinggi $\quad \mathrm{X}$ Kriteria=

Stabilitas

Rentang

stabilitas 
Langkah ke 5

Menentukan kecenderungan jejak data

\begin{tabular}{lccc}
\hline Kondisi & $\mathrm{A} / 1$ & $\mathrm{~B} / 2$ & $\mathrm{~A} / 2$ \\
\hline 4.kecenderungan & $\ldots \ldots$ & $\ldots \ldots$ & $\ldots \ldots$ \\
jekak & $(\mathrm{r})$ & $(\mathrm{)}$ & $($ ) \\
\hline
\end{tabular}

Langkah ke 6

Menentukan level stabilitas dengan rentang

\begin{tabular}{|c|c|c|}
\hline $\mathrm{A} / 1$ & $\mathrm{~B} / 2$ & $\mathrm{~A} / 2$ \\
\hline $\begin{array}{l}\text { 5.Level stabilitas } \quad(\quad) \\
\text { dan rentang }\end{array}$ & ( ) & ( ) \\
\hline $\begin{array}{l}\text { Langkah ke } 7 \\
\text { Menentukan level perubahan }\end{array}$ & & \\
\hline $\begin{array}{lll}\text { Data yang } & \text { Data yang kecil } \\
\text { esar } & & \text { (hari ke...) }\end{array}$ & $\begin{array}{l}\text { Presentasi } \\
\text { stablitas } \\
\text { (hari ke...) }\end{array}$ & \\
\hline
\end{tabular}

Dengan demikian, level perubahan data dapat ditulis seperti berikut ini.

\begin{tabular}{llll}
\hline Kondisi & $\mathrm{A} / 1$ & $\mathrm{~B} / 2$ & $\mathrm{~A} / 2$ \\
\hline Level perubahan rentang & $\ldots \ldots$ & $\ldots \ldots$ & $\ldots \ldots$ \\
\hline
\end{tabular}

a. Langkah-langkah analisis antar kondisi

Langkah-langkah analisis antar kondisi sebagai berikut (Sunanto, et al 2005, 114):

\section{Langkah ke 1}

Menentukan jumlah variable yang diubah

\begin{tabular}{|c|c|c|c|}
\hline Perbandingan kondisi & $\mathrm{A} / 1$ & $\mathrm{~B} / 2$ & $\mathrm{~A} / 2$ \\
\hline $\begin{array}{l}\text { 1.Jumlah variable } \\
\text { diubah }\end{array}$ & yang $\quad \ldots .$. & & \\
\hline
\end{tabular}

\section{Langkah ke 2}

Menentukan perubahan kecenderungan arah dengan mengambil data pada analisis dalam kondisi di atas.

\begin{tabular}{llll}
\hline Perbandingan kondisi & $\mathrm{A} / 1$ & $\mathrm{~B} / 2$ & $\mathrm{~A} / 2$ \\
\hline $\begin{array}{l}\text { 2.Perubahan kecenderungan } \\
\text { arah dan efeknya }\end{array}$ & $\ldots \ldots$ & $\ldots \ldots$ & $\ldots \ldots$ \\
\cline { 2 - 4 } & $(\mathrm{n})$ & $(\mathrm{r})$ & $($ ) \\
\hline
\end{tabular}

Langkah ke 3

Menentukan perubahan kecenderungan stabilitas

\begin{tabular}{llll}
\hline Perbandingan kondisi & $\mathrm{A} / 1$ & $\mathrm{~B} / 2$ & $\mathrm{~A} / 2$ \\
\hline $\begin{array}{l}\text { 3. } \\
\text { Stabilitas }\end{array}$ & $(\mathrm{f})$ & $($ )
\end{tabular}

Langkah ke 4

Menentukan level perubahan

\begin{tabular}{llll}
\hline Perbandingan kondisi & $\mathrm{A} / 1$ & $\mathrm{~B} / 2$ & $\mathrm{~A} / 2$ \\
\hline 2.Perubahan level & $\ldots \ldots$ & $\ldots \ldots$ & $\ldots \ldots$ \\
\cline { 2 - 4 } & $(\mathrm{c})$ & $(\mathrm{c})$ & $($ )
\end{tabular}

Langkah ke 5

Menentukan overlap data pada kondisi baseline (A1) dengan intervensi (B) dan baseline (A2)

\begin{tabular}{lccc}
\hline Perbandingan kondisi & $\mathrm{A} / 1$ & $\mathrm{~B} / 2$ & $\mathrm{~A} / 2$ \\
\hline 5.Presentase overlap & $(\mathrm{r}$ & $(\mathrm{)}$ & $($ )
\end{tabular}




\section{HASIL DAN PEMBAHASAN}

\subsection{Hasil Penelitian}

Penelitian eksperimen SSR pola A-B-A yang telah dilaksanakan ini terdiri dari tiga subjek, akan tetapi proses penelitian ataupun treatmen dilakukan secara individu. subjek mengalami kesulitan dalam mengucapkan beberapa huruf yang bentuk dan bunyinya hampir sama seperti j dengan ذ ذ ל bangan,

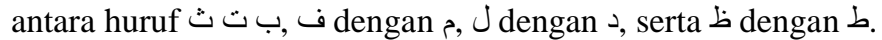

\subsection{Hasil Uji Hipotesis}

Langkah yang dilakukan dalam penelitian ini untuk menguji hipotesis yaitu dengan menganalisis hasil data baseline 1 (A1), Intervensi (B), baseline 2 (A2) menggunakan analisis dalam kondisi dan antar kondisi. Proses analisis grafik selesai, kemudian diuraikan menggunakan statistik deskriptif. Hipotesis yang diajukan dalam penelitian ini adalah Media KîbAr berpengaruh untuk meningkatkan keterampilan membaca bahasa Arab pada anak disleksia di SD Negeri Sempu.

Hasil pengukuran yang telah didapat dalam penelitian ini digunakan untuk mengetahui seluruh hasil penelitian pada ketiga subjek yang sudah dilakukan pada masing-masing kondisi pada tahap baseline 1 (A), intervensi (B), dan baseline 2 (A2) yang dibuktikan dengan deskripsi data hasil pengukuran. Hasil penelitian pada subjek berinisial PAV diperoleh rata-rata skor akumulasi pada fase baseline 1 (A1) sebesar 66,64\%, fase intervensi (B) sebesar 87,47\% dan fase baseline 2 (A2) sebesar 98,61\%.

Hasil penelitian subjek kedua dengan inisial AN, diperoleh rata-rata skor akumulasi pada fase baseline 1 (A1) sebesar 62,47\%, fase intervensi (B) sebesar 80,56\% dan fase baseline 2 (A2) sebesar 93\%. Hasil penelitian subjek ketiga dengan inisial GAS, diperoleh rata-rata skor akumulasi pada fase baseline 1 (A1) sebesar 54,17\%, fase intervensi (B) sebesar 76,38\% dan fase baseline 2 (A2) sebesar 87,37\%. Data tersebut dapat memberikan kejelasan dan menunjukkan bahwa dengan digunakannya media KîbAr dapat memberi pengaruh dalam meningkatkan keterampilan membaca bahasa Arab khususnya huruf hijaiyah pada ketiga subjek karena adanya peningkatan skor dari fase baseline 1 (A1), intervensi (B) dan fase baseline 2 (A2)

\subsection{Pembahasan}

Permasalahan-permasalahan yang telah diuraikan di atas, dapat diatasi dengan diberikan solusi menggunakan media KîbAr. Media KîbAr selain berfungsi untuk membantu menghafal serta memahami huruf hijaiyah baik dari segi makhorijul huruf dan bentuknya juga mempunyai berbagai kelebihan. Proses penelitian ini diperoleh dari penilaian keterampilan membaca huruf hijaiyyah dari tiga subjek. Pertama, subjek inisial PAV pada fase baseline 1 (A1) keterampilan membaca huruf hijaiyah sebelum intervensi menggunakan media KîbAr berada pada rentang 61,34\% hingga 71,94\%. Kondisi intervensi menggunakan media KîbAr dilakukan sebanyak 6 sesi dengan hasil keterampilan membaca huruf hijaiyah yang diperoleh PAV pada rentang 80,6\% hingga 94,34\%. Pengukuran keterampilan membaca hruuf hijaiyah pada baseline 2 dilakukan sebanyak 3 sesi sebagai kontrol setelah diberikan intervensi menggunakan media KîbAr. Hasil keterampilan membaca PAV pada kondisi baseline 2 berada pada rentang $91,11 \%$ hingga $106,11 \%$.

Uraian di atas diketahui bahwa data mean level pada kondisi baseline 1, intervensi dan baseline 2 berturut-turut yaitu $66,64 \%, 87,47 \%$ dan $91,11 \%$. Melalui peningkatan mean level pada setiap kondisi menandakan adanya peningkatan atau membaik. Hal tersebut dibuktikan dengan prosentase yang lebih baik pada kondisi setelah diberikan intervensi (baseline 2 (A2)) daripada kondisi sebelum diberikan intervensi (baseline 1 (A1)) yaitu dari 66,64\% menjadi 91,11\%. Prosentase tersebut menunjukkan selisih atau peningkatan $+24,47 \%$ dari kondisi baseline 1 (A1) ke kondisi baseline 2 (A2). Selain mean level yang meningkat pada setiap kondisi, prosentase data tumpang tindih (overlap) adalah $0 \%$ pada masingmasing kondisi.

Kedua, subjek yang bernama AN memperoleh skor pengukuran keterampilan membaca huruf hijaiyah pada baseline 1 (A1) dilakukan sebanyak 3 sesi berada pada rentang 57,6\% hingga 67,4\%. Selanjutnya pada kondisi intervensi menggunakan media KîbAr yang dilakukan sebanyak 6 sesi dengan hasil keterampilan membaca huruf hijaiyah yang diperoleh AN pada rentang 74,26\% hingga 86,86\%. Pengukuran keterampilan membaca pada baseline 2 dilakukan sebanyak 3 sesi sebagai kontrol setelah diberikan intervensi menggunakan media KîbAr berada pada rentang 85,5\% hingga 100,5\%.

Pelaksanaan kondisi baseline 1 (A1), intervensi dan baseline 2 (A2) ditemukan beberapa kesalahan dalam membaca huruf hijaiyah. Diantara kesalahan yang terdapat pada proses membaca di baseline 1 (A1) yaitu

1) tidak dapat melafalkan bunyi huruf secara tepat berdasarkan bentuk hurufnya yang hampir sama sehingga sering terjadi kesalahan dalam melafalkan dan saling tertukar bunyinya, seperti huruf: 


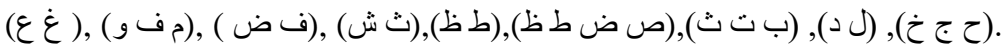

2) berdasarkan bunyinya yang hampir sama sehingga sering terjadi kesalahan dalam melafalkan dan

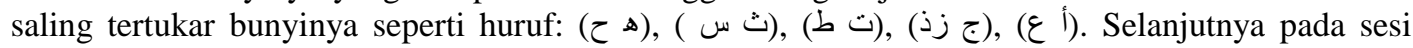
intervensi (pemberian treatment) juga terdapat kesalahan dalam dua hal yaitu melafalkan bunyi yang sama pada huruf yang hampir sama bentuknya dan terbalik melafalkan bunyi huruf yang bentuknya hampir sama.

3) Kesalahan yang terdapat pada sesi intervensi, yaitu 1) kesalahan dalam melafalkan bunyi yang sama

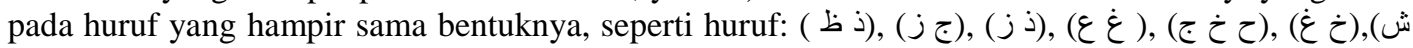
ث), (ت). 2), terbalik melafalkan bunyi huruf yang bentuknya hampir sama, seperti huruf: (ل) (

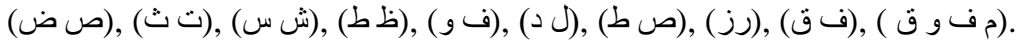

Kesalahan yang ada pada sesi baseline 2 (A2) juga hampir sama dengan kesalahan pada baseline 1 dan intervensi. Proses treatment selesai diberikan menggunakan media KîbAr ada peningkatan dalam melafalkan bunyi huruf serta dapat meningkatkan kemampuan menghafal huruf hijaiyah pada ketiga subjek tersebut. Kesalahannya, yaitu 1) kesalahan dalam melafalkan bunyi yang sama pada huruf yang

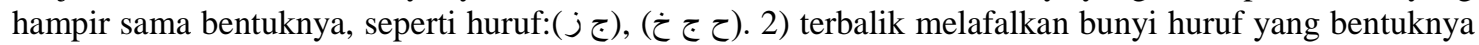
hampir sama, seperti huruf: (ت) (ش س) ( ( ( ). Kesalahan-kesalahan yang terjadi pada sesi baseline 1, intervensi dan baseline 2 disebabkan karena adanya: 1) hambatan fonologis berupa grafem, dan fonem, 2) hambatan system visual pada hurufhuruf kembar.

4.4. Keterbatasan penelitian

1. Keterbatasan waktu penelitian terkait jam belajar siswa di sekolah sehingga kurang maksimal dalam pelaksanaannya.

2. Tidak ada Resource center sehingga kurang nyaman untuk pelaksanaan penelitian.

3. Pada beberapa sesi peneliti berperan sebagai pemberi intervensi sekaligus sebagai pengamat saat proses intervensi sehingga dalam mencatat hasil observasi kesalahan membaca memerlukan koreksi ulang setelah kegiatan intervensi berakhir.

4. Tidak dilakukan uji reliabilitis instrumen, karena tidak ditemukan subjek yang homogen untuk dilakukan uji tersebut.

5. Penelitian hanya dilakukan dalam 6 hari karena mengikuti jadwal sekolah yang cukup padat menjelang pelaksanaan USBN siswa kelas VI di SD Negeri Sempu.

\section{KESIMPULAN}

Hasil penelitian dan pembahasan yang telah dipaparkan pada bab sebelumnya, dapat disimpulkan sebagai berikut. Pertama, Hasil tes membaca yang telah dilakukan pada baseline A-B-A terhadap media KîbAr bahwa ketiga subjek dalam penelitian mengalami kesulitan membedakan bentuk dan bunyi huruf yang hampir sama. Kedua, Faktor penyebab perubahan pelafalan huruf hijaiyah, diantaranya hambatan fonologi, hambatan sistem visual pada huruf-huruf kembar, faktor eksternal dan internal yang dialami anak disleksia. Ketiga, Penerapan media KîbAr berpengaruh untuk meningkatkan keterampilan membaca subjek VAG, AN, dan GAS. Hal tersebut dibuktikan dengan adanya peningkatan prosentase ketercapaian ketiga subjek yang didapat pada setiap fase saat sebelum diberikan perlakuan dan sesudah diberikan perlakuan. Perolehan mean level ketiga subjek pada penelitian ini, yaitu (1) mean level subjek VAG meningkat dari $66,64 \%$ pada kondisi baseline 1 menjadi 87,47\% pada saat intervensi dan $98,61 \%$ pada saat baseline 2, (2) mean level subjek AN meningkat dari 62,47\% pada kondisi baseline 1 menjadi $80,56 \%$ pada saat intervensi dan $93 \%$ pada saat baseline 2, (3) mean level subjek GAS meningkat dari 54, 16\% pada kondisi baseline 1 menjadi 76,4\% pada saat intervensi dan 87,47\% pada saat baseline 2 . Bukti media KîbAr berpengaruh juga didukung dengan presentase overlap yang rendah. Presentase overlap yang diperoleh ketiga subjek antar kondisi baseline 1 dan kondisi intervensi yaitu $0 \%$ serta kondisi intervensi dengan baseline 2 yaitu sebesar $0 \%$

Hasil penelitian dan pembahasan yang telah dijelaskan pada bab sebelumnya menyatakan bahwa media KîbAr memberikan pengaruh membaik pada keterampilan membaca huruf hijaiyah pada anak disleksia, maka peneliti mengajukan beberapa saran yaitu:Bagi Orang Tua. Penggunaan media KîbAr dapat diteruskan dalam pembelajaran membaca huruf hijayah anak disleksia pada saat di rumah dengan bimbingan orang tua. Bagi Guru Kelas. Harapannya dari kesalahan subjek yang telah ditemukan dalam penelitian tersebut agar dapat dijadikan acuan dalam proses pembelajaran khususnya untuk anak disleksia. Bagi Guru Pembimbing Khusus. Harapannya KîbAr dapat diterapkan untuk anak disleksia dengan menggunakan strategi pengajaran seperti yang telah dilakukan dalam proses penelitian tersebut. Bagi Sekolah. Harapannya media KîbAr dapat dijadikan pertimbangan sebagai salah satu media pembelajaran huruf hijaiyah untuk siswa disleksia di SD Negeri Sempu. 
Saran bagi peneliti selanjutnya, sebaiknya pelaksanan penelitian dapat dilakukan sebagai berikut: Memilih waktu yang tepat agar penelitian dapat dilakukan secara efektif dan didapatkan hasil penelitian yang lebih maksimal. Harus dilakukannya kerjasama dan kolaborasi dalam proses penelitian, agar orang tua maupun guru agama dapat melanjutkan bimbingan selanjutnya kepada subjek. Melakukan validasi instrumen agar alat ukur yang digunakan dalam penelitian mendapatksan hasil yang reliabel. Membuat PPI (program panduan individual) yang tepat agar proses penelitian dapat dilakukan secara sistematis dan tidak keluar dari tujuan penelitian. Melakukan assasment kepada subjek agar peneliti dapat melakukan penelitian sesuai kesulitan subjek maupun rekomendasi psikolog.

\section{REFERENSI}

Chaer, Abdul. (2009). Psikolinguistik Kajian Teoritik. Jakarta: Rineka Cipta.

Abdurrahman, Mulyono. (2012). Anak Berkesulitan Belajar; Teori, Diagnosa dan Remediasinya. Jakarta: Rineka Cipta.

Asyrofi, Syamsuddin. (2014). Model, Strategi dan Permainan Edukatif dalam Pembelajaran Bahasa Arab, Yogyakarta:Aura Pustaka.

Darmadi, Hamid. (2014). Metode Penelitian Pendidikan dan Sosial; Teori Konsep Dasar dan Implementasi. Bandung: Alfabeta.

Darwodjo, Soenjono. ( 2008). Psikolinguistik: Pengantar Pemahaman Bahasa Manusia. Jakarta: Yayasan Obor.

Sunanto, Juang., Koji Takeuchi dan Hideo Nakata. (2005). Pengantar Penelitian dengan Subyek Tunggal. Center for Research on International Cooperation in Education Development. University of Tsukuba.

Helmanita, Karlita. (2016). Hambatan Membaca Aksara Arab bagi Anak Disleksia di Sanggar Baca Jendela Dunia. Jurnal Fakultas Adab dan Humaniora Universitas Islam Negeri Syahid Jakarta. Vol.XXII, No.2, Juli 2016. ISSN:08531692 diakses dari bit.ly/buletinaltursa.

Hermawan, Acep. (2018). Metodologi Pembelajaran Bahasa Arab. Bandung: Remaja Rosdakarya.

Latipun. (2015). Psikologi Eksperimen. Malang: UMM Press.

Maherlina Muna, Ayuhana. (2012). "Penerapan Metode KIBAR dalam Pembelajaran Al - Qur'an di TK Plus KIBAR”. Fakultas Tarbiyah dan Keguruan. Universitas Islam Negeri Sunan Kalijaga. Skripsi. Yogyakarta. Diakses dari http://digilib.uin-suka.ac.id.

Melly handayani, Metode Kibar dalam Baca Tulis Qur'an AUD, diakses dari https://mellyhandayanicyrus.wordpress.com/2015/05/16 metode-kibar/, diakses pada tanggal 25 Maret 2019 pukul 13.45 WIB.

M, Aphroditta. (2014). Panduan Lengkap Orang Tua \& Guru untuk Anak dengan Disleksia (Kesulitan Membaca). Yogyakarta: Javalitera. 90

Nurhadi. (2016). Strategi Meningkatkan Daya Baca. Jakarta: Bumi Aksara.

Nursara, Siska. (2018). "Efektivitas Media SAKURA (Susun Huruf, Suku Kata,dan Kata) Berbaris Multisensori untuk Meningkatkan Kemampuan Membaca bagi Anak Disleksia”. Fakultas Keguruan dan Ilmu Pendidikan. Universitas Ahmad Dahlan. Skripsi. Yogyakarta. diakses dari http://digilib.uad.ac.id/.

M. Griffiths, Yvonne and Margaret J. Snowling. (1984). .”Auditory word identification and phonological skills in dyslexic andaverage readers" University of Californi

Diaksesdarihttps://www.cambridge.org/core/journals/applied-psycholinguistics/.

Mar'at, Samsunuwiyati. (2005). Psikolinguistik suatu pengantar. Bandung:Refika Aditama.

Muhammad Sholihuddin, S.Q, "Mengoptimalkan Potensi, hlm 2

Rahim, Farida. (2011). Pengajaran Membaca di Sekolah Dasar. Jakarta: Bumi Aksara.

Sholihuddin, Muhammad, S.Q, "Mengoptimalkan Potensi Anak Menghafal Al- Qur"ān", http://metodeKibAr.blogspot.com/2011/06/mengoptimalkan potensi- anak-menghafal.html, diunduh tanggal 25 Januari 2019.

Syamsuddin, Asyrofi. (2014). Model dan strategi permainan edukatif dalam pembelajaran bahasa Arab. Yogyakarta:Aura Pustaka. 91

Mulyadi (2010) Diagnosa Kesulitan Belajar dan Bimbingan terhadap Kesulitan Belajar Khusus. Yogyakarta: Nuha Litera

Sugiyono (2016). Metode Penelitian Pendidikan; Pendekatan Kuantitatif, Kualitatid, dan R\&D. Bandung; Alfabeta.

Surhasimi Arikunto (2013). Prosedur Penelitian; Suatu Pendekatan Praktik. Jakarta: Rineka Cipta.

Sunanto, Juang., Koji Takeuchi dan Hideo Nakata. (2005). Pengantar Penelitian dengan Subyek Tunggal. Center for Research on International Cooperation in Education Development. University of Tsukuba. 
Tarigan, Hendry Guntur. (2015). Membaca; Sebagai Suatu Keterampilan. Bandung: Angkasa.

Thomson, Jenny. (2014). Memahami Anak Berkebutuhan Khusus. Jakarta: Erlangga.

Snowling, Margaret (1998). "Dyslexia as a Phonological Deficit :Evidence andImplications". Jurnal. University of York. Diaksesdarihttps://www.cambridge.org/core/journals/applied-psycholinguistics/.

Utami ,Sulistiyaning Putri dan Lulus Irawati. (2017). "Baca Tulis pada Anak dengan Gangguan Disleksia”. Jurnal. Universitas PGRI. Madiun. Diakses dari https://www.researchgate.net/publication/326498719. 